\title{
A CONCEPÇÃO DE CIDADES CRIATIVAS SUSTENTÁVEIS
}

\section{THE DESIGN OF SUSTAINABLE CREATIVE CITIES}

Tiago Bitelo da Silva (UNISINOS)

Fabricio Farias Tarouco, Dr. (UNISINOS)

\section{Palavras Chave}

Cidades criativas; Sustentabilidade; Planejamento urbano; Soluções criativas; Urbanismo

\author{
Key Words \\ Creative cities; Sustainability; Urban planning; Creative solutions; Urbanism.
}

\section{RESUMO}

O tema da sustentabilidade tem sido amplamente discutido desde a crise energética dos anos 70, momento em que a humanidade percebeu a importância e necessidade de consumo responsável dos recursos naturais. Nesta oportunidade surgiu também a premissa de que devemos consumir os recursos existentes de forma a satisfazer as necessidades atuais sem comprometê-los para as gerações futuras. Um pouco mais recente, o conceito de 'cidades criativas' surge como pólo irradiador de conhecimento e soluções inovadoras no âmbito das cidades, sendo a sustentabilidade uma pauta importante neste contexto. Entretanto, ao conectar e replicar tais visões, torna-se fundamental uma análise das reais necessidades e iniciativas de cada comunidade, a serem abordadas neste artigo.

\section{ABSTRACT}

The sustainability theme has been highly discussed since the energetic crisis of the 70's. At that time, the importance of responsible consumption of natural resources was realized by humanity. This opportunity also emerged the premise that we should consume the resources in order to meet the needs of the present without compromising the ability of future generation. In recent time, the concept of "Creative cities" emerged as a center of spreading knowledge and innovative solutions for the cities. Additionally, the sustainability is an important concept in this context. However, to connect and replicate this concept is essential analysing the real needs and the initiatives of each community, and this will be treated in this article. 


\section{INTRODUÇÃO}

É consenso, nos dias atuais, que o uso eficiente dos recursos naturais se tornou fundamental para garantir a vida das gerações futuras. $O$ meio ambiente em degradação e o esgotamento dos recursos existentes são em grande parte consequências dos atuais processos utilizados, especialmente, na construção civil e na operação de edifícios, onde há grande consumo de energia e, por consequência, desperdícios.

Segundo Amaral (2013), o meio ambiente propicia as condições de vida no planeta e é do meio natural que são extraídas as matérias-primas mais utilizadas na indústria. Sabendo que os recursos naturais são finitos, ganha visibilidade o conceito de desenvolvimento sustentável, preconizando atender as necessidades atuais da humanidade sem comprometer a disponibilidade de recursos para as gerações futuras. Numa busca pela racionalização dos recursos naturais surgiram diversas frentes que buscaram reconhecer quais seriam os responsáveis pela degradação ambiental, sendo, posteriormente, a construção civil apontada como uma das maiores consumidoras de recursos e geradora de resíduos.

No atual ritmo de desenvolvimento, Vassalo e Figueiredo (2010) destacam que a ONU projeta que no ano de 2050 o planeta terá aproximadamente 2,5 bilhões de habitantes a mais do que hoje, totalizando 9 bilhões de pessoas em todo o globo terrestre. Por volta do ano 2030 há a previsão de que $80 \%$ da população viverá nas cidades. Neste contexto, aceleram-se as demandas relativas ao crescimento do consumo de recursos naturais, ampliando assim a degradação de ecossistemas no ambiente urbano, além das consequências sociais, tais como crescimento desordenado, desqualificação de periferias, aumento do desemprego, criminalidade e pobreza, entre tantas outras.

A cidade sustentável interpretada por Vassalo e Figueiredo (2010) é aquela organizada de modo que seus habitantes tenham a possibilidade de satisfazerem suas necessidades, aliado ao seu bem-estar sem denegrirem o ambiente natural, garantindo especialmente a manutenção dos recursos necessários para a vida presente e futura.

Neste contexto, Costa, Seixas e Oliveira (2009) introduzem o conceito de cidade criativa propondo uma relação entre criatividade e promoção do desenvolvimento urbano, através da valorização das atividades culturais e criativas na promoção econômica e no desenvolvimento territorial. São apontadas três grandes vertentes aplicadas nesta relação: o desenvolvimento de ferramentas e soluções criativas alinhadas aos novos contextos sociais e culturais, o foco na indústria e setores criativos e a capacidade em atrair recursos humanos criativos. Por sua vez,
Moraes e Schwartz (2011) apontam que a cidade criativa é um território vinculado aos fluxos de informação, abrangendo diversas esferas, permeando o virtual e real, público e privado, produção e consumo.

Sendo a cidade criativa um polo irradiador de conhecimento, este artigo irá abordar a questão da sustentabilidade aproximando-a das práticas implementadas nestas cidades, visto que o tema ambiental é uma agenda recorrente e de suma importância em escala global e que pode ser impulsionado com o reforço da criatividade.

\section{A SUSTENTABILIDADE NA ARQUITETURA E NO URBANISMO}

Para Motta e Aguilar (2009), o desenvolvimento da humanidade se baseia em um consumo cada vez maior de recursos naturais, gerando degradação e poluição ambiental, conforme já mencionado. Essas limitações na quantidade de recursos e as mudanças ambientais e climáticas cada vez mais perceptíveis mostram que este quadro é insustentável a médio e longo prazo.

Estima-se que as cidades já utilizam mais de $50 \%$ das fontes mundiais de energia, sendo o setor da construção civil responsável pelo consumo de $40 \%$ dos recursos naturais, $40 \%$ da energia e $40 \%$ das emissões poluentes, tendo consequências desastrosas sobre o meio ambiente (MOTTA, AGUILAR, 2009). Entende-se então que a partir deste cenário a busca por um modo de vida mais sustentável tornará-se cada vez mais presente na sociedade, incluindo-se obrigatoriamente nesta busca a indústria da construção civil.

As consequências apontadas, se nenhuma providência for tomada para o cenário atual, pelo Unep Global Environment Outlook 3 (UN-GEO3, 2002), são de que em torno de $70 \%$ da superfície do planeta e sua vida selvagem sofrerão impactos e poderão ser dizimados até o ano não muito distante de 2032. Nos países subdesenvolvidos ou em desenvolvimento, o quadro é agravado pela alta taxa de urbanização nestes locais, com o aumento da população e o crescimento econômico (CSILLAG, 2007) acelerado.

Uma das primeiras definições de desenvolvimento sustentável foi divulgada pelo Brundtland Report no ano de 1987, onde afimou-se que o desenvolvimento sustentável é aquele no qual as demandas por recursos do presente são atendidas sem comprometer o acesso das gerações futuras a estes recursos (GONÇALVEZ, DUARTE, 2006). Este tema teve em pauta nas décadas seguintes através de conferências de âmbito mundial como a Rio'92, no Rio de Janeiro em 1992, e a Rio+10, em Johannesburgo, em 2002.

O conceito da construção sustentável teve em seu início como foco a concepção de edifícios energicamente mais 
eficientes, necessidade esta advinda da crise do petróleo nos anos 70. Araújo (2008) cita que, com o passar do tempo, as necessidades foram sendo modificadas e o conceito da sustentabilidade na construção passou a abranger outras diretrizes, tais como o entulho gerado nas obras, uso racional da água, os resíduos gerados na operação dos edifícios e as emissões de $\mathrm{CO} 2$ envolvidas em todo o processo.

Conforme Edwards e Hyett (2013), a sustentabilidade posiciona-se cada vez mais como um item de relevância do projeto arquitetônico no século XXI, o qual possui uma dimensão social e também estética, servindo a tecnologia como ligação entre ambas. Trata-se de um novo conceito do projeto de arquitetura no qual há uma conciliação do habitat humano e a natureza. Estes autores apontam que a sustentabilidade é um indicador chave da qualidade do projeto, pois um projeto sustentável deve gerar valor por um período maior de tempo, utilizando os recursos existentes. Também comparam a tríade Vitruviana composta por Firmitas, Utilitas e Venustas com o chamado pilar da sustentabilidade, sendo o viés econômico, social e ambiental as bases da teoria sustentável.

O projeto sustentável deve ser fruto de uma visão holística de pensamento, sem separar os propósitos a serem atingidos. A formação de equipes multidisciplinares, altamente especializadas em áreas distintas da sustentabilidade, pode ser considerada como uma forma de restringir o acesso ao conhecimento e à arquitetura ecológica a proprietários e investidores de alto poder aquisitivo (ARAÚJO, 2008). Por outro lado, ao se disseminar o conhecimento aplicado ao projeto sustentável, este poderá tornar-se de domínio público, sendo um processo cultural da disciplina de projetos.

$\mathrm{Na}$ arquitetura contemporânea observa-se, de forma crescente, o uso intensivo da tecnologia na viabilização de práticas sustentáveis, sendo apontado por Edwards e Hyett (2013) que a tecnologia é o motor mais importante do projeto. Além da tecnologia, há itens normativos que apoiam o projetista ao conceber uma arquitetura sustentável. Araújo (2008) cita as normas ISO 21930 (2007) - Sustentabilidade na construção civil - Declaração ambiental de produtos para construção e ISO 15392 (2008) - Sustentabilidade na construção civil - Princípios gerais. O Comitê Técnico da ISO traz o seguinte conceito para definir as edificações sustentáveis (ARAÚJO, 2008, página 2), no qual verifica-se a importância da relação entre a edificação e o meio urbano e regional:

"Edificação sustentável é aquela que pode manter moderadamente ou melhorar a qualidade de vida e harmonizar-se com o clima, a tradição, a cultura e o ambiente na região, ao mesmo tempo em que conserva a energia e os recursos, recicla materiais e reduz as substâncias perigosas dentro da capacidade dos ecossistemas locais e globais, ao longo do ciclo de vida do edifício (ISO/TC 59/SC3 N 459) ".

Goulart (2010) traz à reflexão o fato de que os projetistas procuram alcançar uma harmonia não somente estética, mas também ecológica entre a edificação e o ambiente natural e urbano onde está inserida. Há uma busca por estratégias a nível urbano, como a minimização das ilhas de calor e impacto no microclima, com o uso dos espaços verdes.

O crescimento urbano vem sendo incrementado nas últimas décadas, segundo Vassalo e Figueiredo (2010) devido ao crescimento econômico, a globalização, ao desenvolvimento tecnológico e a migração das áreas rurais para as áreas urbanas. Este crescimento não foi acompanhado de forma adequada pela gestão pública, ocorrendo então sem um planejamento adequado. Algumas estratégias em resposta a estas questões vêm sendo utilizadas, tais como o incentivo ao uso do transporte público, a promoção de combustíveis menos poluentes, a reciclagem de materais, além de programas de reabilitação de espaços urbanos degradados ou sub-utilizados. Os modelos chamados de Cidades Sustentáveis, Cidades Globais, Cidades Verdes ou ainda Cidades Inteligentes possuem uma finalidade única, que é a de combinar em seus processos a viabilidade econômica com a preservação dos ecossistemas naturais onde foram inseridas, aliada a uma busca pela qualidade de vida de seus habitantes. É a partir desta conexão que se obtém então a tão desejada sustentabilidade urbana.

O modelo de cidade sustentável defendido por Sánchez e Moura (1999) é composto por boas práticas que articulam eficácia energética e qualidade de vida, onde o planejamento urbano é o agente denominador de ações que buscam a redução da degradação ambiental através de tecnologias para reciclagem e despoluição. Estas ações vão desde a educação ambiental, no desenvolvimento da consciência ecológica, até ações estruturais como projetos de técnica urbana.

\section{A SUSTENTABILIDADE DAS CIDADES CRIATIVAS}

De forma complementar, Furtado e Alves (2011) citam que a sustentabilidade ambiental é um fator de competitividade global, sendo que as cidades criativas possuem um papel importante na revitalização dos centros urbanos, visto que o fomento às atividades culturais leva à criação de espaços e equipamentos importantes, trazendo maior vitalidade à cidade, atraindo mais pessoas e diferentes culturas. Para uma abordagem concreta de sustentabilidade nas cidades dos criativos, é necessária uma 
governança democrática que promova estratégias de planejamento urbano aliadas à disponibilidade em trabalhar com recursos e culturas locais.

Uma cidade criativa ecológica pode ser classificada (VASSALO, FIGUEIREDO, 2010) como aquela em que há uma visão aberta de experimentação de todo seu potencial de recursos humanos e tecnologias, possibilitando uma resposta rápida às mudanças necessárias. Sendo assim, deve-se buscar uma redução do impacto ao meio ambiente em um contexto urbano onde haja um equilíbrio entre as áreas construídas, na qual a infraestrutura ofertada deve ser segura e eficiente e as áreas rurais protegidas.

Conforme Sánchez e Moura (1999), as cidades que possuem o reconhecimento de cidade-modelo acabam por ter uma visibilidade de âmbito internacional e uma maior capacidade em atrair investimentos, ganhando um status de "cidades internacionais". Estes modelos têm sido replicados principalmente em itens como programas ambientais de eficiência energética, preservação de áreas verdes, sistemas de transporte e organização de megaeventos.

Quando se trata da preservação de áreas verdes, Lerner (2003) comenta sobre a importância das praças e cita exemplos diversos tipos de intervenções bem-sucedidas, como por exemplo, o Aterro do Flamengo no Rio de Janeiro ou o Central Park de Nova lorque (EUA). Essas praças, conforme o autor, devem ter uma amarração com o tecido urbano onde são inseridas, sendo esta conexão variável conforme o local de sua implantação.

$\mathrm{Na}$ cidade de Bilbao, na Espanha, foi recuperada uma região degradada pela atividade industrial, até então sendo estes antigos espaços compostos por áreas de solos contaminados e ruínas industriais (FURTADO, ALVES, 2011). Estes locais foram totalmente remodelados, atualmente abrigando espaços de lazer, com galerias de arte, zonas de negócios aliados a uma alta qualidade arquitetônica das intervenções. Tais ações tiveram foco nas questões culturais e de sustentabilidade, especialmente nas intervenções de infraestrutura aplicadas ao local.

Em uma intervenção de âmbito nacional, Vassalo e Figueiredo (2010) resgatam o Programa Polis desenvolvido em Portugal, que teve inicio com intervenções urbanas realizadas em 28 cidades do país. O programa contemplou a requalificação de áreas degradadas, valorização do patrimônio histórico e natural, com a recuperação de áreas ribeirinhas e costeiras. A qualidade e a presença de elementos naturais na paisagem urbana foram fundamentais para a preservação do meio ambiente, sendo que o planejamento urbano precisa promover uma conexão entre os diferentes espaços existentes, contribuindo com a biodiversidade.
Já no caso da cidade brasileira de Curitiba-PR, algumas de suas ações sustentáveis e criativas mais populares são a criação de programas de reciclagem de lixo, a valorização e expansão das áreas verdes, os investimentos em educação ambiental e a implantação de parques urbanos temáticos (SÁNCHEZ, MOURA, 1999). Este padrão criado de cidade sustentável insere a mesma em um contexto global, requalificando o ambiente urbano, inspirando orgulho em seus habitantes e trazendo confiança a possíveis investidores.

Lerner (2003) defende também a importância da arborização, onde há exemplos como o de Xangai, que a cada quatro metros, em todas as ruas, há uma árvore se crescendo. Na cidade de Curitiba foram plantadas um milhão de árvores nos últimos anos, sendo lançada pela Prefeitura Municipal a campanha "A Prefeitura dá a sombra e você, a água fresca". Nesta campanha a população foi incentivada a colaborar com o projeto, irrigando e cuidando das árvores plantadas pelo poder público. Também com a finalidade focada em se humanizar uma intervenção, em Curitiba, ao se propor a vegetação dos conjuntos habitacionais os moradores foram os responsáveis pela escolha das espécies vegetais a serem plantadas em suas proximidades, criando uma identidade 'verde' para a região.

Ao tratar de cidades-modelo, Sánchez e Moura (1999) posicionam os casos de Curitiba e Cingapura como referências que tiveram suas soluções urbanísticas criativas replicadas em diversas outras localizades do mundo, representando um novo padrão dominante de sucesso. Entretando, em um contexto de mundo globalizado, estes modelos impõem um modo padronizado que traz uma hegemonia desterritorializada, pois quando ocorre a aplicação destes modelos, são geralmente necessárias grandes mudanças de cunho estrutural a um alto custo, assumidos prioritariamente pela administração pública, sendo necessário, para legitimar estes investimentos, uma conexão entre a intervenção urbanística e a ideologia de comunidade.

Para Furtado e Alves (2011) quando se faz uso da abordagem de cidade criativa na busca de um desenvolvimento sustentável, a Arquitetura é apontada como chave interveniente das ações, já que possui um grande potencial transformador sobre o espaço urbano, indo da escala do edifício ao planejamento urbano. Estas intervenções trazem nova vida a estruturas obsoletas, sendo os empreendimentos ícones atratores de grandes massas.

Girardet (1999) complementa trazendo a questão de que para criar cidades sustentáveis deve haver uma ligação entre o planejamento de usos do solo e o planejamento de recursos, possibilitando o consumo de forma responsável sem prejuízos para as condições de vida de seus habitantes. 


\section{CONCLUSÕES}

O tema da sustentabilidade está em voga no âmbito da arquitetura e urbanismo, tendo avançado muito nos últimos anos, não somente pelo avanço tecnológico em si, mas devido à facilidade de troca de informações típica de um mundo globalizado. A necessidade em se poupar recursos naturais é indiscutível e o planejamento urbano deve tratar o assunto de forma prioritária, por isso justifica-se a proposta deste artigo.

A partir da popularização dos entendimentos de cidades-modelo e cidades criativas, o mundo passou a ter referências de boas práticas aplicadas em diversos contextos urbanos. Estes, relacionados ao planejamento urbano, envolvem soluções em transporte público, zoneamento urbano, gerenciamento de resíduos, entre outras políticas públicas tidas como bem-sucedidas em suas cidades de origem, entre elas estão as cidades citadas aqui. Sendo necessária uma critica à replicação de modelos, conforme apontado, pois cada local possui legislações, morfologias e culturas diferentes que necessitam adaptações ou propostas inéditas. Quando o foco é a reprodução de modelos, um aprofundado estudo das necessidades alinhadas aos interesses das comunidades torna-se fundamental.

Assim, as cidades criativas, tidas como modelos globais em diversos aspectos, podem e devem contribuir na difusão de boas práticas em toda e qualquer área do conhecimento, especialmente quando se busca inovação. Ao exercerem ações de cunho ambiental, colocam a preocupação com o meio ambiente como um modelo a ser seguido, sendo muitas destas, inclusive, tendo como principal imagem a de cidade sustentável.

Como importante referência desta discussão, a cidade de Curitiba é frequentemente apontada como disseminadora de soluções inovadoras, implantadas em sua maioria na gestão do então Prefeito, arquiteto e urbanista Jaime Lerner. Tal cidade tornou-se uma referência nacional e internacional, tendo o título de cidade da qualidade de vida concedido, em 2015, pela Agência Classificadora Austin Ratings e pela revista IstoÉ, após análise de 212 indicadores relacionados às áreas social, econômica, fiscal e digital. Seu sistema de transporte público uma prática exportada para diversos locais, seja no Brasil ou no exterior, além de suas boas práticas na área ambiental.

De forma mais abrangente, as cidades criativas devem prosseguir com suas soluções inovadoras, propondo novas ideias para um mundo cada vez mais conectado. Não somente na área ambiental, conforme apresentado, mas também no desenvolvimento de novas políticas públicas para as demais áreas de um planejamento urbano.

\section{REFÊRENCIAS}

AMARAL, Marco Antônio Teixeira de. Green building: análise das dificuldades (ainda) enfrentadas durante o processo de certificação LEED no Brasil, 2013.

ARAÚJO, Márcio Augusto. A moderna construção sustentável. IDHEA-Instituto para o Desenvolvimento da, 2008.

COSTA, Pedro; SEIXAS, João; OLIVEIRA, Ana Roldão. Das Cidades Criativas à Criatividade Urbana? Espaço, Criatividade e Governança na Cidade Contemporânea. CD de Atas do XV Encontro da APDR subordinado ao tema Redes e Desenvolvimento Regional, realizado em Cabo Verde, p. 6-11, 2009.

CSILLAG, Diana. Análise das práticas de sustentabilidade em projetos de construção latino americanos. 2007. Tese de Doutorado. Universidade de São Paulo.

DEGANI, Clarice Menezes; CARDOSO, Francisco Ferreira. A sustentabilidade ao longo do ciclo de vida de edifícios: a importância da etapa de projeto arquitetônico. São Paulo: Escola Politécnica, Universidade de São Paulo, 2002.

EDWARDS, Brian; HYETT, Paul. Guía básica de la sostenibilidad. Editoria Gustavo Gili, 2004.

FURTADO, Gonçalo; ALVES, Sandra. Cidades criativas em Portugal e o papel da arquitetura: Mais uma estratégia a concertar. Revista Crítica de Ciências Sociais, n. 99, p. 125-140, 2012.

GONÇALVES, Joana Carla Soares; DUARTE, Denise Helena Silva. Arquitetura sustentável: uma integração entre ambiente, projeto e tecnologia em experiências de pesquisa, prática e ensino. Ambiente construído, Porto Alegre, V. 6, n. 4, p. 51-81, 2006.

GOULART, Solange. Sustentabilidade nas Edificações e no Espaço Urbano. Apostila da Disciplina Desempenho Térmico em edificações. Laboratório de Eficiência Energética em Edificações. v. 2, p. 12, 2010. Universidade Federal de Santa Catarina. Disponível em <www. labeee. ufsc. br/graduação/ecv_5161> Acesso em 10/11/2014

LERNER, Jaime. Acupuntura Urbana. Editora Record, 2003. 
MORAES, Julio Lucchesi; SCHWARTZ, Gilson. Cidades criativas e conexão audiovisual. Informações FIPE, 2011.

MOTTA, Silvio FR; AGUILAR, Maria Teresa P. Sustentabilidade e processos de projetos de edificações. Gestão \& Tecnologia de Projetos, v. 4, n. 1, p. 88-123, 2009.

SÁNCHEZ, Fernanda; MOURA, Rosa. Cidades-modelo: espelhos de virtude ou reprodução do mesmo. Cadernos Ippur, v. 13, n. 2, p. 95-114, 1999.

VASSALO, V. P. L.; FIGUEIREDO, P. J. S. Sustentabilidade dos espaços urbanos. In: $4^{\circ}$ Congresso Luso-Brasileiro para o Planejamento Urbano, Regional, Integrado e Sustentável, 2010.

GIRARDET, H. Criar Cidades Sustentáveis, Colecção Cadernos Schumacher para a Sustentabilidade, Edições Sempre-em-pé, 86 p., Lisboa, 2007. 